\title{
Effect of Different Surface Treatments for Ceramic Bracket Base on Bond Strength of Rebonded Brackets
}

Monique Kruger Guarita', Alexa Helena Köhler Moresca', Estela Maris Losso $^{1}$, Alexandre Moro ${ }^{1,2}$, Ricardo Cesar Moresca ${ }^{1,2}$, Gisele Maria Correr ${ }^{1}$
'Graduate Program in Dentistry, UP Positivo University, Curitiba, PR, Brazil ${ }^{2}$ Department of Anatomy and Orthodontics, UFPR Federal University of Paraná, Curitiba, PR, Brazil

Correspondence: Profa. Dra. Gisele Maria Correr, Rua Pedro Viriato Parigot de Souza, 5300, 81280-330 Curitiba, PR, Brasil. Tel:+55-41-3317-3456. e-mail: giselenolasco@up.com.br

Key Words: orthodontic brackets, ceramics, shear bond strength.

\begin{abstract}
The aim of this study was to evaluate the shear bond strength of rebonded ceramic brackets after subjecting the bracket base to different treatments. Seventy-five premolars were selected and randomly distributed into five groups $(n=15)$, according to the type of the bracket surface treatment: I, no treatment, first bonding (control); II, sandblasting with aluminum oxide; III, sandblasting + silane; IV, silica coating + silane; and V, silicatization performed in a laboratory (Rocatec system). The brackets were fixed on an enamel surface with Transbond XT resin without acid etching. The brackets were then removed and their bases were subjected to different treatments. Thereafter, the brackets were fixed again to the enamel surface and the specimens were subjected to shear bond strength (SBS) test. The adhesive remnant index (ARI) was then evaluated for each specimen. Data were subjected to ANOVA and Tukey's tests $(\alpha=0.05)$. A statistically significant difference was observed only between Rocatec and the other groups; the Rocatec group showed the lowest SBS values. The highest SBS values were observed for group 1, without any significant difference from the values for groups II, III and IV. Most groups had a higher percentage of failures at the enamel-resin interface (score 1). It was concluded that the surface treatments of rebonded ceramic brackets were effective, with SBS values similar to that of the control group, except Rocatec group.
\end{abstract}

\section{Introduction}

In the field of esthetic orthodontics, ceramic brackets have proved to be an economically viable option and have been widely studied (1-3). Because of their characteristics, ceramic brackets show satisfactory bond strength with enamel and in some cases higher than the one provided by metallic brackets $(2,4)$.

Owing to the semipermanent nature of orthodontic adhesives, the bracket-enamel bond strength must be sufficiently high to avoid detachment but not too excessive so that it would damage the tooth or restoration during the debonding procedure $(1,5-7)$. Brackets may fail when they are subjected to inappropriate forces or when the adhesive procedure has not been properly carried out. Moreover, changes in bracket positioning during the treatment are very common. Therefore, rebonding of ceramic brackets is a feasible procedure (8).

When bracket debonding is carried out carefully, it becomes possible to reuse the brackets. However, in the case of ceramic brackets, owing to the properties of ceramics, it is not feasible to remove the brackets intentionally to use them for a new bonding. This is because there is a greater probability of fracture or structure damage to a ceramic bracket due the force applied in debonding $(9,10)$. Ceramic brackets can be subjected to the rebonding procedure especially in the case of an adhesion failure without damage to bracket structures. It has been reported that the clamping force can be increased by subjecting ceramic brackets to a surface treatment prior to rebonding; moreover, after such a treatment, the performance of brackets becomes similar to that of new brackets $(4,11)$.

Surface treatments performed on ceramic brackets are aimed at removing surface irregularities at the base of the brackets, thereby increasing retention and bond strength of orthodontic brackets rebonded to enamel. In addition to mechanical retention, some treatments promote chemical bonding by the use of bonding agents between ceramic and resin $(1,2)$.

Various methods have been proposed for the surface treatment of ceramic brackets at their bases, such as grinding with diamond burs, hydrofluoric acid application, silane application, sandblasting with aluminum oxide, and silica coating + silane (silicatization) (1,12-18). Methods to improve the ceramic-resin cement bond strength, especially silicatization performed using laboratory systems, have been evaluated by indirect ceramic restorations $(19,20)$. However, only a few studies evaluated these procedures and reported improvement in the bond strength of ceramic brackets $(1,2)$.

Owing to the various methods for increasing the bond strength of ceramic brackets by surface treatments, the aim of this study was to evaluate the shear bond strength of 
rebonded ceramic brackets after subjecting their bases to different treatments. The null hypothesis is that there is no effect on the bracket among the different superficial treatments.

\section{Material and Methods}

Seventy-five sound human premolars were stored in a 0.5 chloramine-T solution at $4{ }^{\circ} \mathrm{C}$ for a maximum of 6 months after extraction. Exclusion criteria included previously restored premolars, teeth submitted to any chemical treatment and premolars with enamel defects or cracking and delamination of the enamel. Approval was obtained from the Institutional Review Board (Protocol \#044/2011-10) for carrying out this study.

The roots of the teeth were embedded in self-curing acrylic resin (Vipi Flash, Pirassununga, SP, Brazil) using PVC tubes (25 mm diameter and $30 \mathrm{~mm}$ height) as molds. Ceramic brackets (sapphire brackets, MBT .022, Perfect SB Clear Bracket; Hubit Co. Ltd., Seoul, South Korea) were bonded to the buccal enamel surface of the teeth without application of phosphoric acid. Transbond XT Light Cure Adhesive (3M Unitek, Monrovia, CA, USA) was placed on the mesh pad of individual ceramic brackets that were

firmly with a Hollenback carver to expel excess adhesive. Each bracket was subjected to a $300 \mathrm{~g}$ compressive force by using a force gauge (Correx Co., Bern, Switzerland) for $10 \mathrm{~s}$, after which excess bonding resin was removed using a sharp scaler. The position of the brackets was carefully checked with a bracket gauge. The bonding adhesive was light-cured for $5 \mathrm{~s}$ from the occlusal edge and $5 \mathrm{~s}$ from the gingival bracket edge with a LED light-curing unit (Biolux; Bioart, São Carlos, SP, Brazil) with a light intensity of 1000 $\mathrm{mW} / \mathrm{cm}^{2}$, measured using a built-in radiometer every 10 min to ensure consistent light intensity.

The brackets were then removed (debonded) using specific ceramic bracket removal pliers (Orthometric, Marilia, SP, Brazil), following the manufacturer's instructions. Initially, active plier ends were positioned holding the proximal edges of the brackets on the interface with the tooth surface while maintaining a perpendicular relationship with the buccal surface of the tooth. Then, a smooth mesiodistal movement was done, allowing the pliers to remove the brackets without fractures. The enamel buccal surface was analyzed using a stereomicroscope (Olympus SZX9, São Paulo, SP, Brazil) with 12.4× magnification to verify if the entire adhesive was removed without any enamel damage.

The teeth were then randomly assigned into 5 groups $(n=15)$ according to the type of surface treatment employed for the bracket base: I, no treatment, first bonding (control); II, sandblasting with aluminum oxide
$(50 \mu \mathrm{m}) ; \mathrm{III}$, sandblasting with aluminum oxide $(50 \mu \mathrm{m})$ followed by silane application; IV, sandblasting with silica dioxide particles $(30 \mu \mathrm{m})$ (silicatization) followed by silane application; $V$, silicatization performed in the laboratory (Rocatec system), which consisted in sandblasting with aluminum oxide ( $110 \mu \mathrm{m}$, Rocatec-Pre powder), sandblasting with silicic-acid-modified aluminum oxide particles (110 $\mu \mathrm{m}$, Rocatec-Plus powder) and silane application.

In group I, no treatment was carried out on the bracket base. The bonding procedure for group I was the same carried out for the other groups after the brackets base treatments. The sandblasting procedures in groups II, III, and IV were carried out using a intraoral sandblaster (VH Softline, Vh-Grupo Midas Dental Products Ltda., São Paulo, $S P, B r a z i l)$ that was filled with aluminum oxide particles (groups II and III) or silica dioxide particles (group IV). Further, sandblasting was carried out at an incidence angle of $90^{\circ}$ with the bracket base and at a distance of $10 \mathrm{~mm}$ from it, for $20 \mathrm{~s}$ with a pressure of 2.8 bar.

The silicatization procedure was carried out using the Rocatec system (3M ESPE, Monrovia, MN, USA) (group V) in a prosthesis laboratory in accordance with the same protocol regarding incidence angle, distance and pressure.

Different treatments were carried out until the entire adhesive was removed from the bracket base. The complete removal of the adhesive was checked using the stereomicroscope. Thereafter, silane (Silano; Angelus

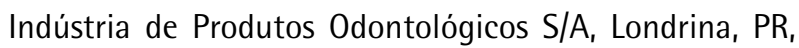
Brazil) was applied with a microbrush on the bracket bases for 1 min (groups II, III, IV and V).

After bracket surface treatments, the buccal enamel surface of each premolar was cleaned with fluoride-free pumice slurry, etched with 37\% phosphoric acid gel (Etch37, Bisco, Schaumburg, IL, USA) for $30 \mathrm{~s}$, rinsed for $15 \mathrm{~s}$, and dried under oil- and moisture-free air for $20 \mathrm{~s}$ until the enamel regained a faintly white appearance. Then, Transbond XT Light Cure Adhesive was applied on the bracket base (for all groups) according to manufacturer's instructions. A thin uniform coat of Thansbond XT Primer was applied on each tooth surface. Then, a small amount of Transbond XT Adhesive was placed onto the bracket base and light-cured for $5 \mathrm{~s}$ from the occlusal edge and $5 \mathrm{~s}$ from the gingival bracket edge. The curing was performed using a light-curing unit (LED Biolux, BIOART) with a light intensity of $1000 \mathrm{~mW} / \mathrm{cm}^{2}$.

The specimens were then stored in deionized water at $37^{\circ} \mathrm{C}$ for $24 \mathrm{~h}$. Thereafter, the specimens were subjected to a shear bond strength (SBS) test.

In the SBS test, the specimens were secured to a jig attached to the base plate of a universal testing machine (EMIC DL 2000, São José dos Pinhais, PR, Brazil). A chiseledged plunger was mounted on the movable crosshead of 
the testing machine and was positioned so that the leading edge was aimed at the enamel-composite interface before coming into contact with the specimen. The crosshead speed in the test was $0.5 \mathrm{~mm} / \mathrm{min}$. After debonding, each specimen was examined under the stereomicroscope to identify the location of bond failure. The residual composite remaining on the premolar was assessed using the adhesive remnant index (ARI) (22). For awarding this index, each specimen was scored according to the amount of material remaining on the enamel surface as follows: 0 , no adhesive remaining; 1 , less than $50 \%$ of the adhesive remaining; 2 , more than $50 \%$ of the adhesive remaining; and 3 , all of the adhesive remaining with a distinct impression of the bracket base.

The obtained data (SBS values) were subjected to oneway analysis of variance and Tukey test $(\alpha=0.05)$. The ARI values were analyzed for determining the percentage and frequency of the fracture type, and were subjected to the chi-square test. All the statistical analyses were performed using BioEstat 5.0 software (Sociedade Civil Mamirauá, Tefé, AM, Brazil).

\section{Results}

\section{Shear Bond Strength}

Mean bond strengths and standard deviations for each group are listed in Table 1. A statistically significant difference was found among the groups $(p=0.0001)$. The highest SBS values were observed for group I (control, first bonding); however, no significant difference was observed among groups I, II, III and IV. The Rocatec system (group V) showed the lowest SBS values that were significantly different from those for the other groups.

\section{Adhesive Remnant Index}

The distribution of failure modes, as expressed by ARI scores (\%), is given in Figure 1. According to the statistical analysis (chi-square analysis) of the ARI scores, all the test groups exhibited similar bracket failure modes $(p=0.065)$. Most groups showed higher percentage of failures in the

Table 1. Mean (MPa) and standard deviation of shear bond strength (SBS) values for the different bracket base treatments

\begin{tabular}{ll}
\hline Treatment & SBS at 24 h \\
\hline 1 - Control (new brackets) & $30.41(2.28) \mathrm{A}$ \\
II - Sandblasting & $24.52(4.71) \mathrm{A}$ \\
III - Sandblasting + silane & $27.53(4.21) \mathrm{A}$ \\
IV - Silica coating + silane & $28.12(6.41) \mathrm{A}$ \\
V - Rocatec & $14.22(3.36) \mathrm{B}$ \\
\hline
\end{tabular}

Different letters indicate statistically significant difference (Tukey's test $-\mathrm{p}<0.05)$. enamel/resin interface, with less than $50 \%$ of the adhesive remaining (score 1). No enamel fractures were observed in any of the tested specimens.

\section{Discussion}

In orthodontic practice, surface treatment of the ceramic bracket base is effective for enabling bracket rebonding in cases of a bonding failure. The cost of using new brackets for replacement, especially ceramic brackets, can be high. Therefore, an alternative treatment should be sought in order to sustain a viable reuse of brackets.

Shear strength values above $8 \mathrm{MPa}$ are considered adequate for most clinical needs, because this load is sufficient to withstand masticatory and orthodontic forces (22). According to the results of this study, all the evaluated surface treatments were effective, with SBS values close to that of the control group, thereby confirming the viability of bracket rebonding. These results agree with those reported in another study (4), in which aluminum oxide sandblasting followed by silane application group resulted in SBS values statistically similar to those for new bracket groups.

In this study, the shear bond strength means followed a decreasing order: group I (new brackets, control), followed by groups IV (silicatization), III (sandblasting + silane), II (sandblasting), and V (Rocatec), respectively. These results corroborate those reported in other studies $(1,17)$, in which a similar ranking was found for various surface treatment groups. However, another study (8), involving similar surface treatments groups, reported better results for the Rocatec group than those observed in the present study. The reason for these findings may be related to the type of the evaluated material (metallic brackets). In this study, the authors explained their results by assuming that silica deposition over the entire surface of the bracket base followed by the silane-coupling agent application would result in chemical bonding between the resin and silica (8).

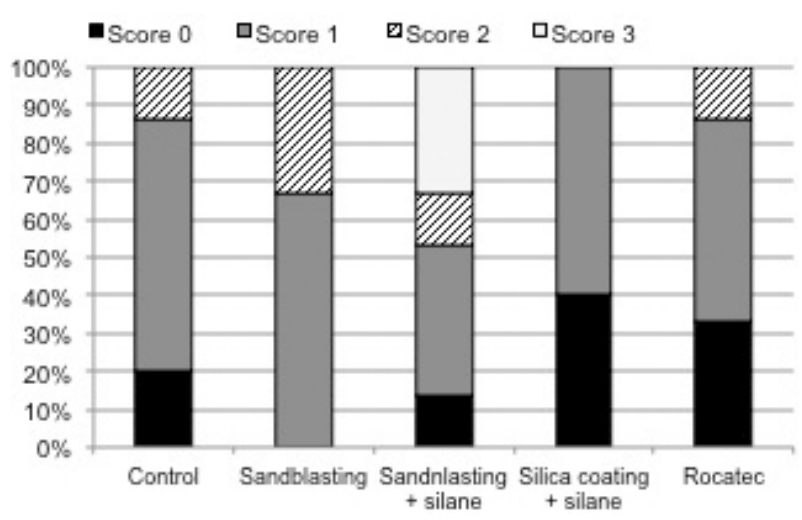

Figure 1. Distribution of failure modes and ARI scores (\%) obtained after the SBS test. 
In the present study, the Rocatec group values, which were the lowest ones, were significantly different from those for the other groups, refuting the hypothesis of this study. However, the mean value of SBS for this group was 14.05 $\mathrm{MPa}$, which is sufficient for clinical use. This result may be due to differences in the Rocatec system itself (equipment and particle size used), although the treatment involved the same incidence, duration and pressure settings. The silica coating using the Rocatec system was the only treatment performed by another operator, because of the need to send the brackets to a prosthetic laboratory.

It should be pointed out here that although it is possible to use the Rocatec system for bracket base surface treatment, this procedure is not clinically viable. This treatment involves sending the brackets to a laboratory for treatment and therefore bracket rebonding is not possible in the same session.

According to the results, there was no statistically significant difference among groups I, II, III and IV. This result shows that all treatments, except Rocatec, were effective in fulfilling the main purpose of surface treatment, i.e., to remove the remaining adhesive from the accessory and to expose the bracket surface again for bonding. Thus, it is possible to obtain a good result by using a simple method such as aluminum oxide sandblasting.

Many studies have reported that good bond strength results can be obtained by subjecting the bracket base only to aluminum oxide sandblasting $(2,4,17)$. Regarding other treatments, the application of silane after sandblasting with aluminum oxide did not show improved results; moreover, the results were not significantly different from the control group. This must be due to the fact that aluminum oxide sandblasting only cleans the bracket base by physical action and does not form a chemical bond with sapphire brackets, which have a monocrystalline structure with no glass in the composition. Further, silicatization (silica coating + silane) did not show significantly different results from the control group. In addition, silicatization requires specific products and is costly.

The IRA results were predominantly score 1, i.e., less than $50 \%$ of adhesive adhered to the enamel. This proves that the bond between the resin and bracket was effective for all groups, validating the surface treatment. Other studies that used ceramic brackets also reported a predominance of failures at the enamel-resin interface $(1,23)$.

When failure occurs at the enamel-resin interface with less than half of the remnant adhesive adhered to the enamel, the need to wear out the remaining adhesive is low, and thus, the possibility of damage to the enamel is also low (24). Egan et al. (25) concluded that the procedure of bracket rebonding is a viable option, especially when failure occurs at the resin-enamel interface, thus validating the results found in this study.

For orthodontists, it has become important to know surface treatments for the ceramic bracket base because rebonding of ceramic brackets with adhesion failure can help them avoid the cost of new brackets. Moreover, these treatments may keep the bracket accessories firmly adhered to the enamel during treatment by resisting orthodontic and masticatory forces.

As demonstrated in this study, many surface treatments for the ceramic bracket base are available and can be employed for successful bracket rebonding. However, treatments performed in the clinic using an intraoral blaster are simple and can be safely performed by any professional.

Based on the results of this study, it may be concluded that the different surface treatments for rebonded ceramic brackets were effective to clean the bracket base and promote adequate bond strength. The aluminum oxide sandblasting is a simple, effective, and low-cost procedure for ceramic bracket rebonding in clinical practice.

\section{Resumo}

0 objetivo do estudo foi avaliar o efeito de tratamentos da base de bráquetes cerâmicos monocristalinos na resistência de união ao esmalte após recolagem. Setenta e cinco pré-molares foram selecionados e aleatoriamente distribuidos em 5 grupos $(n=15)$ de acordo com 0 tratamento da base do bráquete: I - sem tratamento, primeira colagem (controle), II - jateamento com óxido de alumínio, III - jateamento seguido da aplicação de silano, IV - jateamento com partículas de dióxido de sílica (silicatização) seguido de silano, V - silicatização realizada em laboratório (Sistema Rocatec). Os bráquetes foram colados no esmalte com Transbond XT sem condicionamento ácido. Em seguida, os bráquetes foram removidos e suas bases foram submetidas aos diferentes tratamentos. Os bráquetes foram recolados, armazenados por $24 \mathrm{~h}$ e submetidos ao ensaio mecânico de cisalhamento com velocidade de $0,5 \mathrm{~mm} / \mathrm{min}$. Após, $o$ indice de remanescente adesivo (IRA) foi avaliado em cada espécime. Os dados foram submetidos à análise de variância e teste de Tukey $(\alpha=0,05)$. Pode-se observar que houve diferença significativa apenas entre o sistema Rocatec e os demais grupos, o qual apresentou os menores valores de resistência. Os maiores valores de resistência foram observados para o grupo I (controle), sem diferença significativa dos grupos II, III e IV. A maioria dos grupos apresentou maior porcentagem de falhas na interface esmalte/resina (escore 1). Pode-se concluir que os tratamentos da base do bráquete cerâmico foram efetivos, apresentando valores similares ao grupo controle, exceto para o grupo em que foi usado Rocatec.

\section{References}

1. Atsu SS, Gelgor IE, Sahin V. Effects of silica coating and silane surface conditioning on the bond strength of metal and ceramic brackets to enamel. Angle Orthod 2006;76:857-862.

2. Toroglu MS, Yaylali S. Effects of sandblasting and silica coating on the bond strength of rebonded mechanically retentive ceramic brackets. Am J Orthod Dentofacial Orthop 2008;134:181e1-e7.

3. Reddy YG, Sharma R, Singh A, Agrawal V, Agrawal V, Chaturvedi S. The shear bond strengths of metal and ceramic brackets: An in-vitro comparative study. J Clin Diagn Res 2013;7:1495-1497.

4. Chung $\mathrm{CH}$, Friedman D, Mante F. Shear bond strength of rebonded mechanically retentive ceramic brackets. Am J Orthod Dentofacial Orthop 2002;122:282-287.

5. Tavares SW, Consani S, Nouer D, Magnani MBBA, Pereira Neto JS, Romano F. Evaluation in vitro of the shear bond strength of aluminum 
oxide recycled brackets. Braz J Oral Sci 2003:2:378-381.

6. Montasser MA, Drummond JL, Roth JR, Al-Turki L, Evans CA. Rebonding of orthodontic brackets: Part II, an XPS and SEM study. Angle Orthod 2008;78:537-544.

7. Knosel M, Mattysek S, Jung K, Kubein-Meesenburg D, Sadat-Khonsari $\mathrm{R}$, Ziebolz D. Suitability of orthodontic brackets for rebonding and reworking following removal by air pressure pulses and conventional debracketing techniques. Angle Orthod 2010;80:649-655.

8. Faltermeier A, Behr M. Effect of bracket base conditioning. Am J Orthod Dentofacial Orthop 2009;135:12e1-e5.

9. Matasa GC. Pros and cons of the reuse of direct-bonded appliances. Am J Orthod Dentofacial Orthop 1989;96:72-76.

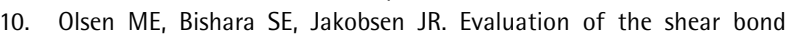
strength of 14 different ceramic bracket base designs. Angle Orthod 1997;67:179-182.

11. Montasser MA, Drumond JL, Evans CA. Rebonding of orthodontic brackets. Part I, A laboratory and clinical study. Angle Orthod 2008;78:531-536.

12. Newman SM, Dresseler KB, Grenadier MR. Direct bonding of orthodontic brackets to esthetic restorative materials using a silane. Am J Orthod Dentofacial Orthop 1984;86:503-506.

13. Kern M, Thompson VP. Sandblasting and silica-coating of dental alloys: volume loss, morphology and changes in the surface composition. Dent Mater 1993;9:155-161.

14. Aida M, Hayakawa T, Mizukawa K. Adhesion of composite to porcelain with various surface conditions. J Prosthet Dent. 1995;73:464-470.

15. Barbosa VL, Almeida MA, Cheviterese 0 , Keith 0 . Direct bonding to porcelain. Am J Orthod Dentofacial Orthop 1995;107:159-164.

16. Newman GV, Newman RA, Sun BI, Ha JJ, Ozsoylu SA. Adhesion promoters, their effect on the bond strength of metal brackets. Am J Orthod Dentofacial Orthop 1995;108:237-241.
17. Karan S, Büyükyilmaz T, Toroglu MS. Orthodontic bonding to several ceramic surfaces: Are there acceptable alternatives to conventional methods? Am J Orthod Dentofacial Orthop 2007;132:144e7-e14.

18. Atsu S, Çatalbas B, Gelgor IE. Effects of silica coating and silane surface conditioning on the bond strength of rebounded metal and ceramic brackets. J Appl Oral Sci 2011;19:233-239.

19. Perdigão J, Fernandes SD, Pinto AM, Oliveira FA. Effect of artificial aging and surface treatment on bond strengths to dental zirconia. Oper Dent 2013;38:168-176.

20. Blatz MB, Chiche G, Holst $\mathrm{S}$, Sadan A. Influence of surface treatment and simulated aging on bond strengths of luting agents to zirconia. Quintessence Int 2007;38:745-753.

21. Artun J, Bergland S. Clinical trials with crystal growth conditioning as an alternative to acid-etch enamel pretreatment. Am J Orthod 1984;85:333-340.

22. Reynolds IR. A review of direct orthodontic bonding. $\mathrm{Br} \mathrm{J}$ Orthod 1975;2:171-179.

23. Harari D, Gillis I, Redlich M. Shear bond strength of a new dental adhesive used to bond brackets to unetched enamel. Eur J Orthod 2002;24:519-523.

24. Costa AR, Correr AB, Puppin-Rontani RM, Vedovello SA, Valdrighi HC, Correr-Sobrinho $L$, et al.. Effect of bonding material, etching time and silane on the bond strength of metallic orthodontic brackets to ceramic. Braz Dent J 2012;23:223-227.

25. Egan FR, Alexander SA, Cartwright GE. Bond strength of rebonded orthodontic brackets. Am J Orthod Dentofacial Orthop 1996;109:6470.

Received May 14, 2014 Accepted December 11, 2014 